bell hooks

Berea College, Berea, Kentucky

\title{
Escolarizando homens negros
}

(c) $(1)$ Esta obra tem licença Creative Commons.

' bell HOOKS, 2004

${ }^{2}$ HOOKS, 2000

${ }^{3}$ Marília Pinto de CARVALHO, 2004a, p. 274; 2004b, p. 31.

\section{Apresentação}

No terceiro capítulo do livro We Real Cool: Black Men and Masculinity, bell hooks, ${ }^{1}$ intelectual, acadêmica e feminista estadunidense, pesquisa livros críticos e autobiográficos elaborados por intelectuais negros e destaca reflexões, memórias e relatos sobre infância, juventude, escolarização, processos de socialização e de formação intelectual entre homens negros. Privilegiando o estilo ensaístico, pode-se ver neste capítulo um excelente esforço de operacionalização de perspectivas analíticas e políticas do feminismo negro, discutindo criticamente o sexismo, o racismo e a desigualdade de classe como lógicas de ação, de pensamento, de exploração e de opressão, atuantes nos mecanismos de socialização de diferentes sujeitos. ${ }^{2}$ Por outro lado, ao identificar estereótipos raciais e de gênero como práticas que atuam na formação de identidades sociais do sujeito durante sua vida escolar, esta perspectiva analítica vai ao encontro da ideia na qual a heteroidentificação racial e de gênero pode ser tecida também com relação ao desempenho escolar, imputando ao sujeito um status racial cuja consequência política pode ser a responsabilização por seu desempenho na escola, por meio de seu maior ou menor "compromisso" com a instituição. ${ }^{3}$

Algo equivalente a este registro pode ser visto no que bell hooks define como blame the victim: o sujeito passa a ver o seu desempenho escolar apenas como resultado de seu comportamento individual, de modo que forças sociais externas ao eu individual, vividas na escola, deixam de ser vistas como determinantes de sua trajetória. De todo modo, com a tradução deste texto para a língua portuguesa, pretende-se registrar uma grande contribuição do pensamento feminista negro aos estudos sobre gênero, raça e educação que poderá ser acessado por professores, pesquisadores e estudantes. 


\section{Escolarizando homens negros}

Mais do qualquer outro grupo de homens em nossa sociedade, os homens negros são muitas vezes concebidos como sujeitos desprovidos de habilidades intelectuais. Sob a visão estereotipada do racismo e do sexismo que os veem como mais corpo do que mente, homens negros estão propensos a serem recebidos pela sociedade da supremacia branca capitalista, imperialista e patriarcal, como sujeitos que parecem ser idiotas ou, como nós que crescemos nos anos 1950 costumávamos dizer, pessoas lentas (isto é, pouco inteligentes). Na infância, era óbvio para todos em nosso bairro negro que, quando um homem negro pensava demais, ele passaria a ser visto como uma ameaça pelo mundo racista. Não havia correlação entre a habilidade de uma pessoa para pensar, para processar ideias e nível de escolaridade. Homens negros bemeducados tinham aprendido a atuar como incultos, iletrados e ignorantes em um mundo onde um negro inteligente corria o risco de ser punido.

Desde a escravidão até os dias atuais, alguns homens negros têm estado na vanguarda dos esforços que os afroamericanos têm realizado para adquirir educação em todos os níveis. Em fins do século XIX e começo do século XX, qualquer homem negro que procurasse passar da escravidão para a liberdade via a educação como uma saída. Durante esse período, a falta de recursos materiais frequentemente obrigava as famílias negras a mandar as meninas para a escola e a empurrar os garotos para procurar trabalho. Richard Wright ${ }^{4}$ na autobiografia Black Boy, publicada em 1930, descreve sua vergonha sobre a pobreza e a resultante escassez de

${ }^{4}$ Sobre Richard Wright: http:// www.portaldaliteratura.com/ autores. php? autor $=1853$. [Nota da Redação]

${ }^{5}$ No fim do século XIX, os estados do Sul, afetados economicamente com o fim da escravidão promulgaram as chamadas leis Jim Crow, uma série de determinações para legitimar a discriminação racial e dificultar o acesso dos negros ao voto. [N. R.] roupas e livros: "Eu iniciei a escola no Instituto Howard em uma idade mais tardia do que a habitual; minha mãe não tinha sido capaz de comprar as roupas necessárias para me fazer apresentável." Como muitas famílias negras sofrendo de dificuldades econômicas, a família de Wright mudava de casa com muita frequência, o que significou que sua escolarização era constantemente interrompida. "Embora eu tivesse quase nove anos de idade, eu não tinha tido um único ano ininterrupto de escola, e eu não tinha consciência disso. Eu podia ler e contar e isso era o que a maioria das pessoas que eu conhecia poderia fazer, fossem adultos ou crianças." No mundo Jim Crow ${ }^{5}$ da pós-escravidão, o povo negro tinha que lutar pelo direito de educar a si mesmo. E mesmo quando se obtinha este direito, a imediata necessidade por bens para sobrevivência frequentemente interrompia os esforços dos homens negros em adquirir educação.

Atualmente, na cultura da supremacia branca capitalista, imperialista e patriarcal, a maioria dos jovens 
oriundos das classes pobres e desprivilegiadas é socializada através da mídia de massa e de uma educação elitista tendenciosa para acreditar que tudo o que é necessário para a sua sobrevivência é ter habilidade para o trabalho físico. Jovens negros, desproporcionalmente numerosos entre os pobres, vêm sendo socializados para acreditar que a força e a resistência física são tudo o que realmente importa. Esta socialização é tão presente no mundo atual quanto durante a escravidão. Preparados para ser mantidos como membros permanentes de uma subclasse, para não ter escolhas e, deste modo, dispostos a matar, sempre que necessário, em nome do Estado, homens negros sem privilégios de classe sempre têm sido os alvos da deseducação. Eles foram e são ensinados que o "pensar" não é um trabalho valioso, que o "pensar" não os ajudará a sobreviver. Tragicamente, muitos homens negros não têm resistido a esta socialização. Não é um mero acidente que homens negros com intelectual brilhante acabaram presos, mesmo quando garotos, por serem considerados ameaçadores, maus e perigosos.

Durante os períodos sombrios da legalmente sancionada segregação racial, da discriminação e da opressão, homens negros de todas as classes estavam conscientes da necessidade de resistir a estes estereótipos. Eles estavam conscientes de que abraçar o estereótipo poderia ser fatal. Biografias e autobiografias de homens negros que conseguiram transcender à pobreza em que nasceram contam histórias de indivíduos que lutaram para educar a si mesmos no interior de sistemas educacionais que não os apoiavam. Richard Wright aprendeu a ler no começo da infância, e gostava de ler e pensar. Mesmo assim, isso o colocou em desacordo com um mundo racista branco que apenas queria um negro para ser obediente e idiota. Wright recorda que a leitura de livros Ihe proporcionou uma visão diferente sobre a vida, pois, ao imaginar a si mesmo como um escritor, ele "manteve viva a esperança". Os livros the ensinaram que existiam diferentes perspectivas a se ter sobre a vida. Confessando que queria que sua vida tivesse sentido, ele escreveu: "Eu estava construindo em mim um sonho no qual todo o sistema educacional do Sul tinha sido equipado para reprimir... Eu estava começando a sonhar os sonhos que o Estado tinha dito que estavam errados". Um leitor e pensador, Wright era constantemente interrogado por colegas e professores que procuravam silenciá-lo. Eles queriam saber "porque você faz tantas perguntas?".

Wright está contando uma história real sobre o encontro de um jovem homem negro com o sistema escolar público na década de 1920, mas homens negros de todas as idades

${ }^{6}$ Website de Ellis Cose: http:// elliscose.com/bio/. [N. R.] contam a mesma história atualmente. Compartilhando memórias de seus dias de escola, Ellis Cose ${ }^{6}$ escreve que quando 
olha para trás, percebe que crianças negras e pobres "eram consideradas essencialmente não ensináveis". Como Wright, ele recorda a pequena afirmação do seu desejo de aprender: "Aquela experiência na escola primária tornou difícil para mim a tarefa de levar a escola a sério. Eu nunca fui um mau estudante, mas eu simplesmente não via a escola como um local onde aconteceria meu aprendizado ou onde meus pensamentos seriam ampliados. E quanto mais escolarização eu recebia, mais esta afirmação era confirmada". Como Wright, Cose foi repreendido por ser um pensador, por fazer perguntas: "Lá estava o professor, no terceiro ou no quarto ano, que dizia à classe que os negros tinham línguas preguiçosas. Era a sua maneira, eu acho, de tanto nos desafiar como de nos tranquilizar, de fazer com que nos sentíssemos confortáveis com as nossas deficiências em leitura e pronúncia... Logo houve a professora da sétima série que me criticou quando eu questionei o nível do material de leitura de classe. Sim, ela concordou, os livros foram escritos para alunos do quinto ano, mas, para ela, nós não tínhamos capacidade de lidar nem com material da quinta série, o melhor que eu deveria fazer era calar a minha boca e ser grato à escola que tinha sido digna em dar livros a todos nós". Em várias outras vezes, quando nos contam suas histórias de vida, homens negros descrevem que foram punidos nas escolas porque se atreveram a questionar e a pensar.

A curiosidade que pode ser considerada um sinal de genialidade em uma criança branca é vista como um problema ou dificuldade quando expressada por meninos negros. Escrevendo sobre a sua infância na década de 1950, o poeta e educador Haki Madhubuti conta como suas atitudes com a educação foram transformadas por meio da leitura da história de Richard Wright. Ele relembra: "Aos 13 anos minha mãe pediu que eu fosse à Biblioteca de Detroit pegar um livro para ela. O título do livro era Black Boy, de Richard Wright. Eu recusei ir porque eu não queria ir a lugar nenhum para perguntar qualquer coisa sobre Black. O autoódio que ocupava minha mente, corpo e alma simplesmente me proibia... Eu e milhões de outros jovens negros éramos produtos de um sistema educacional branco que na melhor das hipóteses nos ensinou a ler e a respeitar a literatura, criatividade, ciência, tecnologia e o desenvolvimento comercial de outros. Na verdade, ninguém disse para os homens 'você deve se odiar'. Todavia, imagens, símbolos, produtos, criações, promoções e autoridades da América branca, fossem de modo sutil ou de modo bastante aberto, estavam me ensinando sobre supremacia branca, estavam me ensinando a me auto-odiar". A leitura de Black Boy permitiu a Madhubuti aprender a ser um pensador critico: "Pela primeira vez na minha vida eu estava lendo palavras 
7 Website de Nathan McCall: http:/ /nathanmccall.net/. [N. R.]
${ }^{8}$ Sobre Jarvis Jay Masters: http:// www.freejarvis.org/. [N. R.] transformadas em ideias que não eram insultantes para minha própria pessoa... Ao completar a leitura de Black Boy... Eu tornei-me de algum modo um crítico diferente na escola e em casa". Estudantes negros, como Madhubuti, com frequência compartilham uma realidade na qual professores negros sem consciência estereotipam os jovens negros tal como fazem professores não negros.

Escrevendo sobre o esforço para se educar na década de 1980, em sua autobiografia Makes Me Wanna Holler, Nathan McCall ${ }^{7}$ descreve a perseguição racial que ele vivenciou como um menino de onze anos em uma escola predominantemente branca: "Eu era o único afro-americano na maior parte das minhas aulas. Quando eu me dirigia pra a minha sala de aula e me sentava, os estudantes próximos a mim se levantavam e se afastavam... Lidar com os professres brancos não era melhor que isso. Sempre que possível eles evitavam manter o contato de olho a olho... Era demais para um menino de onze anos desafiar, então eu não tentei. Em vez disso, eu tentei me tornar invisível. Eu ficava comigo mesmo, mantendo-me calado durante as discussões de classe e nunca fazia perguntas nas aulas ou depois delas. Mantinha meus olhos colados em minha mesa ou olhava para frente para evitar chamar a atenção sobre mim. Eu passava os dias na escola tropeçando, adormecido e afastado". A família McCall era composta do pai e da mãe. Seus pais não eram pobres. Eles queriam que McCall tivesse êxito na escola e, durante algum tempo, ele foi obrigado a ter sucesso escolar. Quando McCall deixou esta escola para frequentar outra com mais estudantes negros, ele escolheu sair com os garotos legais depois das aulas em vez de estudar: "Depois que eu comecei a sair, a ideia de escola mudou completamente para mim. Ela parecia mais como uma arena social do que um lugar para aprender. O rigor acadêmico perdeu o seu brilho e a recompensa de ser escolhido para o quadro de alunos de honra não significava mais a mesma coisa. Subitamente, eu não queria ser visto carregando muitos livros, sentindo-me bem autoconsciente para participar das discussões em sala de aula". McCall viu seu afastamento da educação como rejeição a um mundo cuja mensagem indicava que ele não pertencia e não poderia pertencer a tal mundo, não importando o grau de sua inteligência.

Na autobiografia Finding Freedom: Writings From Death Row, Jarvis Jay Masters ${ }^{8}$ lembra que no início de sua infância tinha uma convicção que o fazia acreditar que não poderia evitar o sofrimento. Ele chegou ao corredor da morte com mínimas habilidades de leitura e escrita. Sendo filho de uma mãe solteira, viciada e violenta, ele nunca considerou a educação como algo que poderia modificar sua realidade. Ele acreditava que estava condenado: "Olhando para trás, 
${ }^{9}$ Sobre Huey Newton: http:// www.biography.com/people/ huey-p-newton-37369. [N. R.] percebo que não era a raiva o que me motivava, apesar de ter me escondido atrás da raiva para evitar certas verdades sobre minha vida. Lembro que certa vez, caminhando pela rua, deparei-me com uma pequena árvore crescendo no pavimento de um estacionamento entre os carros. Minha primeira reação foi observá-la, estudá-la, admirá-la. Pensei: 'Como isso é possível?'. Mas isso não foi na escola, pois jamais aprenderia essas coisas. Esmaguei a pequena árvore porque eu sabia que eu nunca iria para a escola. Não havia espaço para questionamento em minha vida". Criado em um orfanato, como um jovem adolescente negro, Masters viu a si mesmo como um prisioneiro. Ele se desesperou em uma idade precoce. Wright, que confrontou um sistema de opressão de raça e classe mais brutal do que o de Masters, teve que aprender ainda como criança a vencer o sistema. Ele leu livros que o ensinaram a ter esperança. Masters recuperou sua esperança apenas quando adulto, no corredor da morte, onde ele se educou, onde os livros ajudaram-no a liberar seu espírito. Incisivamente, Ellis Cose descreve a maneira pela qual ele aprendeu a ser "tão desconfiado da escola, tão alienado de seus métodos e tão convencido de que era muito inteligente para estar lá, que eu poderia estar lá, mas não estava disposto a dar-lhe o meu coração". No ensaio Fear and Doubt, Huey Newton ${ }^{9}$ escreve sobre os caminhos que homens negros pobres precisam percorrer para obter a educação mesmo que eles temam falhar: "Eles dizem aos seus filhos que as coisas serão diferentes para eles se forem pessoas educadas e preparadas, porém não há absolutamente nada nesta advertência que possa estimular os seus filhos a gostar da educação. As populações negras valorizam extremamente a educação, mesmo os negros das mais baixas classes econômicas, ao mesmo tempo em que são temerosos diante da possibilidade de ter seus medos comprovados". Esses sentimentos sobre a escolarização na infância são expressos por homens negros em todas as aulas e classes. No livro de memórias de minha infância de menina, escrevo sobre o tempo em que frequentávamos escolas majoritariamente de pessoas negras, onde os meninos negros eram excelentes e considerados mais inteligentes do que a mais inteligente garota e a maneira como isso mudou depois que as escolas foram integradas. Professores brancos não estavam ansiosos para ensinar meninos negros e pais brancos não estavam ansiosos para ter garotos negros sentados ao lado de seus filhos e filhas. Subitamente, jovens negros inteligentes tornaram-se invisíveis. Quando era permitido a um garoto negro "notável" fazer parte de uma turma de alunos talentosos, isto ocorria apenas depois dele ter provado a si mesmo que poderia ser apropriadamente subordinado. Invariavelmente, ele seria o único garoto inteligente a obter êxito, a aprender a 
ser obediente, a manter sua boca fechada. Garotos negros inteligentes que buscaram ser ouvidos, antes e agora, foram frequentemente expulsos, considerados encrenqueiros e colocados em classes de baixo rendimento ou em classes especiais que são meros espaços de confinamento para aqueles garotos considerados delinquentes. Indivíduos pobres e jovens de classes trabalhadoras que demonstram excelência acadêmica no sistema de ensino público, que não perderam seu espírito e sua integridade, usualmente conseguem fazer isso porque contam com um defensor, um pai, um protetor ou um professor, que intervém quando este tendencioso sistema educacional os ameaça com a destruição.

Uma das principais razões que fez com que o Movimento Black Power escolhesse o trabalho de organização de aulas de reforço em escolas públicas foi o reconhecimento de que o sistema educacional era falho; não somente porque deixava de educar negros pobres, mas porque estava satisfeito com esse fracasso, acomodado em culpabilizar a vítima. Meninos negros de seis, sete e oito anos poderiam ser culpados porque não sabiam ler ou escrever? Quando a escravidão terminou em 1865 e quatro milhões de pessoas negras foram libertadas, a maioria delas não sabia ler ou escrever. De acordo com o censo de 1900, 57\% dos homens negros eram analfabetos. Agora que nos aproximamos do início do século XXI, homens negros compõem uma enorme porcentagem no universo daqueles que são analfabetos. Sendo incapazes de ler e escrever ou possuindo habilidades rudimentares, homens negros insuficientemente educados não estão preparados nem para entrar nas fileiras do desemprego, nem para permanecer nelas. Antes mesmo de encontrar uma cultura de rua genocida, garotos negros têm sido atacados na primeira infância por um genocídio cultural que se inicia nas instituições educacionais, nas quais eles simplesmente não são ensinados.

Comprometida em criar livros que representem o jovem

${ }^{10}$ O livro poderá ser acessado em: Save-pdf.com/download/BE-BoyBuzz-Paperback.pdf. [N. R.] homem negro e os localize no centro das histórias universais, eu escrevi um livro infantil chamado Be Boy Buzz, ${ }^{10}$ que é uma representação positiva de uma individualidade holística da criança. As crianças representadas são negras. O ilustrador do livro é um homem branco. Quando as primeiras ilustrações me foram mostradas, eu notei que muitas das imagens eram de garotos negros que estavam em movimento, correndo, pulando e brincando; eu solicitei imagens de meninos negros parados, curtindo a solidão, lendo. A inclusão da imagem de um menino lendo era particularmente importante porque é óbvio que esta sociedade envia às crianças negras a mensagem de que elas não precisam ser leitoras. Em algumas famílias negras, onde a leitura é encorajada para as meninas, 
"Série de televisão estadunidense sobre uma família afro-americana que vive na cidade de Chicago. A série foi exibida entre 1989 a 1998 pelos canais $C B S$ e $A B C$. Steve Urkel é um dos três filhos de um casal negro de classe média $e$ retrata um jovem negro inteligente e, por isso, estranho e desajeitado. [N. R.] um menino que goste de ler é percebido como suspeito, como aquele que está sendo encaminhado para ser um "maricas". Por certo, uma vez que pessoas negras compram a noção de uma masculinidade patriarcal, para a qual um homem de verdade é um corpo sem mente, garotos negros que são intelectuais, que querem ler e que querem amar os livros, correram o risco de ser ridicularizados como não masculinos. Por certo, as representações televisivas sobre homens negros estudiosos em comédias e seriados (por exemplo, Urkel em Family Matters)" sugerem que um homem negro estudioso é uma aberração, um mostro. Pais permitem que garotos negros consumam esta imagem negativa e depois perguntam por que seus filhos não querem ser alunos sérios e leitores engajados.

A leitura tem sido uma fundamental fonte de conhecimento, poder e liberação para os homens negros, especialmente para vários homens negros que estão aprisionados. Simultaneamente, muitos homens negros responsáveis e desempregados são iletrados e não tem acesso a uma estrutura educacional que possa ensiná-los a ler e a escrever. Eles também podem ser consumidos por sentimentos de vergonha, porque não dominaram essas habilidades em sua juventude, e se recusam a buscar a educação enquanto adultos. Homens negros adultos que estão presos, com tempo em suas mãos, frequentemente não apreciam a oportunidade de aprender habilidades de escrita e leitura. Todavia, eles deveriam ter aprendido estas habilidades na escola, no início de suas vidas.

Aprender a ler e a escrever são habilidades básicas que são necessárias se uma pessoa quiser trabalhar e ser um cidadão plenamente produtivo. Estas habilidades não são ensinadas para a maioria dos homens negros. O sistema educacional não consegue transmitir ou inspirar a aprendizagem em homens negros de todas as idades. Ao mesmo tempo, muitos homens negros formam-se no ensino médio com nível de leitura e escrita de terceira ou quarta série. As exigências do trabalho e da família podem forçá-los a parar de ler e escrever completamente, de modo que eles podem perder as habilidades que tiveram, em vez de construir outras habilidades. Eu tenho ensinado muitos jovens negros em salas de aula, grandes leitores e escritores, os quais simplesmente param de ler uma vez que eles entram no mundo do trabalho. Eles dizem que não tem tempo para ler. Também relatam que a leitura faz com que sintam mais estresse, especialmente quando se trata de assuntos que geram mais sentimentos de impotência e desesperança. Eles preferem usar o seu tempo livre com a diversão, sobretudo por considerarem que a leitura não é uma atividade prazerosa.

Diferentemente dos homens da geração de meu pai, que acreditavam na possibilidade de serem pensadores e 
${ }^{12}$ Ebonics ou Black English são variações vernáculas oriundas do inglês saxônico e de idiomas africanos, elaboradas historicamente na diáspora negra, lidas ora como afirmação identitária, ora como guetização cultural. Ver: James BALDWIN (1997) e Geneva SMITHERMAN (1997). [N. R.]

13 "Vadia" substitui o termo ho, usado por homens para se referir de modo chulo à parceira sexual. [N. R.]

${ }^{14}$ William H. GRIER; Price M. COBBS, 1968. [N. R.] intelectuais orgânicos, o foco do homem negro contemporâneo é fazer dinheiro. Quando os homens da geração do meu pai chegavam em suas casas, vindos dos empregos braçais de baixa remuneração, eles procuravam se engajar em diálogos sérios. Eles liam jornais, livros. $\mathrm{E}$, muitas vezes, não permitiam que as pessoas brancas para as quais eles trabalhavam soubessem que eles eram "pensadores". Novamente, uma distinção deve ser feita entre ser educado e ser um pensador crítico, alguém que reflete sobre o mundo.

Hoje, muitos homens negros inteligentes, que têm sido bem educados, sabem que não devem ser pensadores críticos e eles não tentam ser. Um homem negro, mesmo aquele que é educado, que pensa criticamente, ainda é considerado com desconfiança pelo mainstream cultural. Muitas vezes homens negros educados em empregos bem pagos aprendem a assumir uma atitude de "concordar para estar bem", para não representar uma ameaça aos seus colegas de trabalho brancos. Um homem negro solteiro, acima de 30 anos, trabalhando em um ambiente predominantemente feminino e branco, estava, muitas vezes, sendo tratado como um objeto sexual. Uma jovem mulher branca escreveu à ele recados na versão dela de Black English ${ }^{12}$ dizendo que ela estava "disposta a ser sua vadia". ${ }^{13}$ Apesar de ciente do sexismo racializado no gesto dela, ele sentiu que se não tomasse aquilo como uma mera piada, poderia parecer como um jogador que não trabalha em equipe ou alguém que não sabe lidar com as diferenças em um grupo. Todavia, este homem negro de classe média que nunca tinha falado Black English estava sendo forçado a assumir um lugar [ghetto rap] de negro, o que significava que ele, para seus colegas, era um verdadeiro negro.

Apesar de escutarmos inúmeras vezes que homens negros privilegiados assumem o estilo garoto gangster do gueto (gangsta boy style), raramente ouvimos falar sobre a pressão que eles recebem das pessoas brancas para provar que são "negros de verdade". Esta pressão é parte de um arsenal psicológico racial que constantemente permite às pessoas negras educadas, especialmente homens negros, saber que nem o maior nível de educação alcançado lhes permitirá escapar da imposição de estereótipos racistas. Muitas vezes, em contextos educacionais predominantemente brancos, homens negros assumem o papel de menestrel do gueto como um modo de se proteger da raiva racializada e branca. Eles querem parecer inofensivos, não ameaçadores, e, para fazê-lo, precisam entreter as pessoas ignorantes, deixando-as saber que "Eu não acho que sou igual a você. Eu sei o meu lugar. Mesmo que eu seja educado, sei que você pensa que eu ainda sou um animal no coração". Em Black Rage, os psiquiatras William Grier e Price Cobbs ${ }^{14}$ 
${ }^{15}$ Pode ser acessado em: http:// www.scu.edu/civilsocietyinstitute/ events/upload/LosingtheRace.pdf. [N. R.] descrevem o que eles chamam de "um homem negro paradigmático". Este homem é sempre descrito como "gente boa" por pessoas brancas. Seja qual for o ambiente de trabalho integrado no qual ele atue, ele é o padrão contra o qual os outros negros são avaliados e medidos. Se todos fossem como ele, tudo estaria muito melhor. Ele é passivo, não assertivo e não agressivo. Ele se conduz a partir de uma identificação direta com o seu agressor, assumindo uma maneira aduladora e compatível. Ambientes educacionais racialmente enviesados, frequentemente, exigem que homens negros atendam a esses requisitos de modo a provar que eles são ensináveis, que eles podem aprender. Em estruturas educacionais segregadas, a simples realidade era aceitar que homens negros poderiam e seriam academicamente excelentes. Isto é uma das razões que fazem com que muitos movimentos de pais negros apoiem a criação de escolas segregadas. Durante os anos de segregação racial legalizada, ninguém nas comunidades negras via a educação como uma "coisa de branco".

Durante o período pós-1960 da integração racial, pessoas negras educadas muitas vezes assimilaram a lógica da supremacia branca dominando os povos negros que eram considerados inferiores. Estas atitudes fizeram com que muitos negros marginalizados educacionalmente começassem a ver um negro educado como um inimigo. Anti-intelectualismo abunda na cultura como um todo. Por causa disso, pessoas negras, especialmente aquelas que viviam em um mundo segregado onde o acesso à educação não era simples, que não foram educadas, estavam predispostas a suspeitar de pessoas negras educadas. O polêmico direitista John McWhorter em Losing the Race: Self-Sabotage in Black America ${ }^{15}$ explicita, de um modo útil, que o povo negro "tem herdado o anti-intelectualismo dos séculos de marginalização", mas falha em não fazer a conexão entre o antiintelectualismo entre os negros com o anti-intelectualismo global, presente na cultura. McWhorter passou grande parte de sua vida entre os brancos educados, sendo incapaz de criticar o anti-intelectualismo que é ensinado pelos meios de comunicação de massa, especialmente a televisão. Ele insiste que o "anti-intelectualismo não é imposto sobre os negros pelos brancos, mas transmitido como um traço cultural". É óbvio que, ao fazer este esclareciment, o McWhorter teve que ignorar o legado acadêmico e intelectual dos afro-americanos antes dos anos 1960.

O anti-intelectualismo nas comunidades negras é frequentemente uma arma usada na luta de classes entre aqueles negros que se sentem condenados a uma existência limitada porque eles não são educados e, portanto, são incapazes de ser negros em ascensão, mas que estão se 
${ }^{16}$ Don L. LEE. From Plan to Planet: Life Studies: The Need for Afrikan Minds and Institutions. Detroit: Broadside Press, 1973. [N. R.]

${ }^{17}$ No original, bell hooks usa expressão "99 years" para se referir a pena de prisão perpétua. [N. R.] esforçando para estar na classe profissional gerencial. Estes negros educados de classes privilegiadas tenderam a considerar os incultos com desprezo. E o inculto tem respondido com o mesmo desprezo. Todavia, escutamos mais sobre o segundo do que sobre o primeiro. Muitos jovens ativistas do movimento Black Power eram ávidos leitores. Eles eram pensadores críticos bem-educados. Alguns deles eram intelectuais orgânicos. Não havia anti-intelectualismo em seus escritos e qualquer relação entre ser bem educado e ser branco. No mundo da escolarização racialmente integrada, acadêmicos negros que adquiriram educação como um instrumento de mobilidade social, muitas vezes, desvalorizam seus aprendizados quando conversam com negros incultos. Muitas vezes negros com formação acadêmica superior sentem-se alienados da comunidade negra. Quando recebem a oportunidade de se socializar e se vincular com outras pessoas negras, eles podem depreciar a educação como um modo de se conectar com um mundo negro antiintelectual. Isto é também uma estratégia para serem classificados como superiores. Eles mantêm sua posição de elite negra excepcional ao serem os guardiões que acumulam o conhecimento das formas de educação que lhes dá poderes, enquanto fingem que isto é insignificante.

Os que defendem a autodeterminação dos povos negros têm priorizado sempre a ligação entre a educação e o desenvolvimento de uma consciência e pensamento críticos. De fato, os defensores do movimento Black Power foram muitas vezes críticos da formação deficitária de pessoas negras no sistema educacional existente, apoiando a construção de escolas progressistas para negros. No início da década de 1970, o livro de Don L. Lee, From Plan to Planet: Life Studies: The Need for Afrikan Minds and Institutions, ${ }^{16}$ centrouse na necessidade de educação. Instigando homens negros a criar estruturas educacionais progressivas, ele escreve: "Onde os homens negros estão sendo treinados? A maior parte, nas esquinas das ruas e nas prisões. Porque nossos irmãos não desenvolvem um nível de consciência negra fora dos lugares nos quais eles geralmente se desenvolvem? Porque a maioria dos irmãos obtêm sua consciência política dentro de prisões depois que a prisão perpétua tenha lhes dado um tapa? ${ }^{17}$ Bem, certamente porque nós temos falhado em construir as instituições adequadas para educar e redirecionar nossos homens... Em nossa nova sabedoria, é fundamental que iniciemos a institucionalização de nossos pensamentos e ações e nós precisamos de instituições para isso". Don L. Lee (rebatizado Haki Madhubuti) fundou escolas progressistas.

Na visão inicial sobre a construção destas instituições, uma visão que ele compartilhou com outros homens negros antirracistas, ele associou a criação de escolas com o nacio- 
nalismo negro. A integração levou muitos negros a abandonar o nacionalismo negro porque ele estava associado ao separatismo. Enfrentando a falha da escolarização na educação dos homens negros, hoje, alguns indivíduos, especialmente os que são afrocêntricos, defenderam as escolas separadas. Frequentemente, escolas separadas para meninos negros são apresentadas como a melhor alternativa educacional por causa da ênfase dada à rigorosa disciplina ao invés da aprendizagem. Muitas vezes, não é o rigor que leva estes garotos a dar o melhor de si nestas escolas, mas sim o fato de que os educadores estão sendo cuidadosos, atenciosos, fazendo com que eles se sintam como alunos que podem se sobressair academicamente. Meninos individualmente educados em ambientes favoráveis muitas vezes regridem quando entram em escolas de predominância branca onde são classificados de modo estereotipado como aqueles que não conseguem aprender.

Programas de alfabetização de massa, especialmente os que visam os homens negros desempregados, que associam a aprendizagem ao desenvolvimento de um pensamento crítico, são necessários para corrigir as falhas da escolarização inicial. A educação doméstica, bem como a formação de escolas privadas progressistas que educam para a consciência crítica são alternativas importantes para homens negros. Se homens negros podem educar e/ou reeducar a si mesmos em prisões, então é completamente possível que as pessoas negras preocupadas com essa situação possam educar corretamente estes homens negros durante a infância nas comunidades ou residências onde vivem. Em subculturas onde tal escolarização já está ocorrendo, meninos negros e homens negros reivindicam sua vontade de aprender e de ser educados, apesar das tentativas da sociedade em esmagar o espírito e silenciar mentes que questionam. A escolarização progressiva de homens negros pode se tornar norma apenas quando nós começarmos a levar a educação à sério, restaurando a ligação entre aprendizagem e libertação.

\section{Referências}

BALDWIN, James. "If Black English isn't a Language, then Tell Me, What is?" The Black Scholar Studies and Research, v. 27, p. 5-6, 1997.

CARVALHO, Marília Pinto de. "O fracasso escolar de meninos e meninas: articulações entre gênero e cor/raça". Cadernos Pagu, v. 22, p. 247-290, $2004 a$.

"Quem são os meninos que fracassam na escola?" Cadernos de Pesquisa, v. 34, n. 121, p. 11-40, jan./abr. 2004b. 
GRIER William H.; COBBS, Price M. Black Rage. New York: Basics Books, 1968.

HOOKS, bell. Feminism is for Everybody: Passionate Politics. Cambridge, MA: South End Press, 2000.

"Schooling Black Males". [Escolarizando homens negros]. In: We Real Cool. Black Man and Masculinity. New York/London: Routledge, 2004. p. 32-43. SMITHERMAN, Geneva. "Black Language and the Education of Black Children: One Mo Once." The Black Scholar Studies and Research, v. 27, p. 28-35, 1997.

[Recebido em 12 de janeiro de 2015 e aceito para publicação em 24 de abril de 2015]

Tradução de Alan Augusto Ribeiro e Keisha-Khan Y. Perry 